\title{
Assessment of AL-Hartha Steam Power Station Using Energy and Exergy Analysis
}

\author{
Abdullah N. Fadhil ${ }^{1}$, Assist. Prof. Abdulwadood S. Shihab ${ }^{2}$, Dr. Safaa H. Faisal ${ }^{3}$ \\ ${ }^{1}$ M.Sc Student, Thermal. Mechanics, Eng Dept. Southern Technical University \\ ${ }^{2,3}$ Thermal. Mechanics, Eng Dept. Southern Technical University Basra, Iraq
}

\begin{abstract}
One of the most important topics in the field of thermal engineering is the possibility of making the performance of thermal units to be at the best possible and more efficient. This is due to the high cost of energy and the depletion of fossil fuel resources. The objective of the present work is to conduct a field study through daily follow-up of AL-Hartha power station in Basrah City-Iraq, under operation for a full year of 2016. This is to discover the reality of the station capacity, to consider its real performance and to identity the locations through the station components of useful loss/destroyed energy and exergy for restoring it to enhance the efficiency. To achieve this goal, a presence co-location was performed together with the station employers to get all the information related to the station and to follow up its daily operation along one year. A mathematical model was constructed and verified to simulate all thermal processes anywhere in the operating unit. This simulation was based on the energy and exergy analysis. The complete computer coding and graphing were performed using Engineering Equation Solver (EES) software. It is noticed that AL-Hartha Station of four production units, is currently operating with one unit only. This unit actually operates at $60 \%$ of its design capacity, generating $120 \mathrm{MW}$. Results showed that the actual overall thermal efficiency of this unit is $33 \%$ with an exergitic efficiency of $30.6 \%$. The actual thermal energy lost at the condenser alone is $51 \%$ of the fuel energy (low grade energy at a $23{ }^{\circ} \mathrm{C}$ to $41{ }^{\circ} \mathrm{C}$ ), $0.88 \%$ in the blow down, $7 \%$ at the exhaust gases (high grade energy at $151^{\circ} \mathrm{C}$ ). The total amount of the destroyed exergy is $253.6286 \mathrm{MW}$ and the lost exergy is estimated to be $18.712 \mathrm{MW}$. The most important sites affecting the exergitic performance is the boiler sector which caused 90.3\% of the total destructed exergy mainly at the boiler coils and then at the fuel burners. The second component in the order that affect the station performance is the turbine sector, which caused $5.475 \%$ of the total destructed exergy.
\end{abstract}

Keywords: Energy, Exergy, Irreversibility, Exergy efficiency, Energy losses, Exergy losses, Thermal station.

\section{INTRODUCTION}

Claim for electric power is constantly increasing over human life, and along with it, environmentally friendly and efficient way to generate electricity is becoming more significant. Require for electricity is growing worldwide at a speedy rate (IES, 2012) [1]. It was reported in the international energy statistics in 2012 that about $73.5 \%$ of the total electricity production in all parts of the world, comes from conventional thermal plants that rely on fossil fuels. With the percentage of electricity production all over the world from fossil fuels, the use of effective resources in this sector is crucial. To utilize fossil fuels cleanly and professionally in producing electricity, hard work are frequently spent to pick up the efficiency and performance of available power plants by modernize and develop, and to build up advanced fuel utilization technologies. Owing to this fact, and the widely utilization of steam power plants all over the world for producing electricity, it has been studied in a number of research projects with the primary focus on the alternative design and operation analysis of the plant that are under operation to increase the net efficiency.

Nowadays, electrical utilities are motivated to improve the efficiency of old on hand power stations, it is much easier than some of the difficult choices. Frequently, efficiency improvement even with low percentages, sends a pleasure compared to the complexity and costs. To support efficiencies improvement of electricity generation technologies, the thermodynamic performances of power 
generation systems are usually investigated normally using traditional energy analysis method. This method involves the energy balance based on the first law of thermodynamics (FLT), it is used to establish and decrease lost energy and occasionally to recover exhausted heat. On the other hand, analysis that based only on FLT does not give any indication to the extent of the energy level declination during operations as well as it does not specify the quality of energy at different locations of the working fluid streams. It is possible to overcome the shortage in the first law and access to a broader understanding of thermal processes when the adoption of a comprehensive analysis through the application of exergy analysis. Exergy analysis is based on both the FLT and the SLT. It takes into account the energy losses due to irreversibilities and to indicate clearly the location of energy declines during the operations, and also can determine the quality and value of the exhausted heat. It helps to identify the responsibilities among the plant components for the major exergy destruction and losses.

Rosen compared nuclear verses coal-fired steam power stations and showed the overall energy and exergy efficiencies was $37 \%$ and $36 \%$ respectively, the thermal efficiencies for each station were $30 \%$ [2]. S. Sengupta et al. study 210 MW power station under operation at different loads and showed that the greatest exergy destruction was in the boiler which was of about $60 \%$ and the irreversibilities of the cycle increased with part load operation [3]. Isam H. Aljundi performed an analysis based on energy and exergy principals showed that the greatest energy losses of $134 \mathrm{MW}$ were in the condenser and only $13 \mathrm{MW}$ was lost at the boiler. The maximum exergy destruction of $77 \%$ was found in the boiler and then by $13 \%$ in the turbine and then only $9 \%$ in the forced draft fan condenser. The obtained thermal efficiency of the cycle was $26 \%$ while the exergy efficiency was $25 \%$ [4]. In (2016), Gholam Reza and Davood Toghraie performed a thermodynamic analyses for 200 MW power station using energy and exergy principals. The results showed that the condenser caused $69.8 \%$ of the heat losses which represent the main of the total lost heat, while it had only $1.53 \%$ of the total exergy lost. The boiler caused only $10.16 \%$ of the total heat lost and $85.66 \%$ of the total exergy lost. The plant energy efficiency was calculated as $32 \%$ while its exergitic efficiency was $35.2 \%$ [5].

\section{AL-Hartha Steam Power Station}

AL-Hartha steam power station is situated in the AL-Hartha quarter of Basrah city on the west bank of the Shatt al-Arab, about $20.5 \mathrm{~km}$ northeastern of the Basrah center. AL-Hartha station has four power generating units of $200 \mathrm{MW}$ for each unit (nominal rating). The total installed generating capacity of the station is about $800 \mathrm{MW}$. The station was established in 1979 by Mitsubishi company. It works with different fuel type liquid fuel (like crude oil and gas oil), gas fuel (like natural gas). The plant currently receives crude oil from Bazargan oil field that located on the Missan production field. The station was commissioned in 1979 and operated as a base load plant until 1980. The station was hit by more than one incident that destroyed important parts of it. It underwent during these periods to attempts to return some of its units to work and concluded at the end to the operation of the first unit. It should be noted that AL-Hartha Unit No.1 has never had a complete rehabilitation, since the unit's original commissioning date.

\subsection{Description of AL-Hartha Steam Power Station}

The operating unit No. 1 which is concerned in this study has been divided into sections. Note that wherever through the following, when the term "power station" is mentioned, it refers to the production unit No. 1 under study.

\subsubsection{Power Generation Section}

The power station, see Fig.(2), have three turbines (high pressure, intermediate pressure and law pressure) which are impulse-reaction type. The high and the intermediate turbines are enclosed in the same cylinder, the low pressure turbine cylinder is a double flow chest, so the turbines are two cylinder, single reheat, condensing double flow chest. The turbines contain six stages of steam bleeding with design generating power of $200 \mathrm{MW}$ at 0.08 to 0.152 bar condenser pressure. Rotor gland is a place in the turbine cylinder which insulate the turbine cylinder from the output to prevent the steam of HPT (High pressure turbine) to vents to the surrounding. In the LPT (Low pressure turbine) a similar gland prevent the air enter to the condenser due to the vacuum in the condenser. The 
generator is an AC type use the hydrogen for cooling, it rotates at constant speed $3000 \mathrm{rpm}$ to give 50 $\mathrm{Hz}$ at $18 \mathrm{KV}$ which is then converted by the transformer to high voltage of $400 \mathrm{KV}$.

\subsubsection{Pumps and Feed Water Heater Section}

At this section two pumps are installed, they are; Condensate feed water pumps (CP) (two pumps) which are installed to discharge the feed water stream from the condenser hot well to the low pressure FWH (Feed water heater) at pressure of 19 bar. Boiler feed water pumps (BFP) (Three pumps, always two in work) which are installed to discharge the water from deaerator to the high pressure $\mathrm{FWH}$ ) at pressure of 185 bar.

AL-Hartha Steam power station has six FWH. A set of three low pressure closed FWH; one intermediate pressure open FWH (deaerator) and a set of two high pressure closed FWH.

A fractions of superheated steam that extracted from the low pressure turbine are bled to a set of three low pressure closed feed water heaters which are FWH1, FWH2, and FWH3 at different pressure level from various points of the LPT. The condensate at the exit of each FWH is trapped to the one before to feed the collected water back to the condenser at the hot well. A fraction of superheated steam that extracted from the Intermediate pressure turbine is bled into an open feed water heater (FWH4), it mixes with the feed water stream (point 33) and intensifying its temperature. The water out of the open FWH is pumped to word the boiler passing throughout a laid down two closed FWHs (FWH5 and FWH6), one of them receives a fractions of superheated steam that is extracted from the intermediate pressure turbine while the other receives a fraction of superheated steam from the high pressure turbine, this is for further heating of the feed water stream. The condensate at the exit of the closed FWH6 is trapped to the one before (FWH5) to feed it back to the open feed water heater. Trapping processes let the liquid to be throttled to a lower pressure section excluding the vapor.

\subsubsection{Boiler Section}

The boiler section, see Fig.(2) consists of Heat exchanger (boiler Coils); economizer, steam drum, 1st super heater, 2nd super heater, 3rd super heater and reheater. It also consists of two forced draft fan (FDF), two Gas circulation fan (GRF), steam-air preheater (SAH), Oil preheater $(\mathrm{OH})$, two rotary air pre heater (APH), Burner (contain 12 burners which is at the four corner of the furnace with three levels). The boiler section (or steam generator, as it commonly called) that used in AL-Hartha power station is natural circulation boiler with forced draft, it is gas and oil fired system, generating steam at $538 \mathrm{oC}$ and 125.5 bar. It is water tube boiler (this type is used for high pressure application). This boiler is also used for reheating process of the steam that existing out of the high pressure turbine up to a temperature of $538 \mathrm{oC}$.

\subsubsection{Condenser Section}

The condenser is a shell and tube type with design vacuum pressure of $700 \mathrm{mmHg}$, this vacuum is made by steam air ejector and by keeping low cooling temperature of the cooling medium (river water stream). The vacuum at the condenser help in releasing as much as possible of energy of the expanded steam through the turbine. A steam jet air ejector (SJAE) is used to vent out the non-condensable gases that implemented to the working fluid due to vacuum.

The tube side of the condenser have 11312 tube separated into two parts A and B. The cooling water pump is a vertical type single impeller receives the water from the river and sent it to the condenser. The cooling water is then directed back to the river through a long channel to reduce thermal pollution.

Within the condenser there is a collector immersed in the condensate water called Flash box, it is connected to the condenser space through two pipes, upper and lower, the upper pipe is to pass steam and the lower one is to pass the condensate water. The Flash box receives the return steam/liquid from the operation processes such as GSC, SJAE, extraction lines, by pass system, control valve, etc. The condensate water out of the condenser is collected in a hot well then it is pumped by the condensate pump to feed it to the boiler through a series of FWHs. 


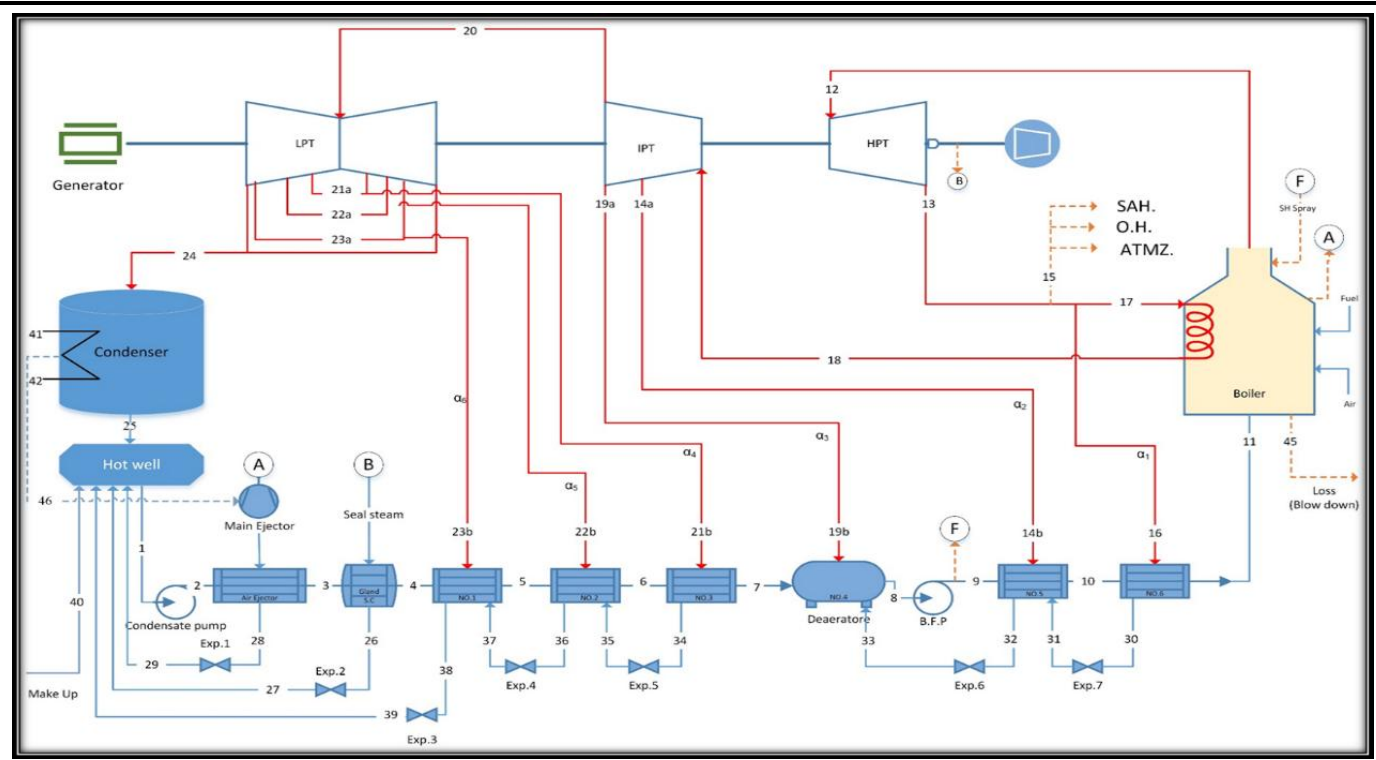

Fig1. Schematic diagram for AL-Hartha Station layout

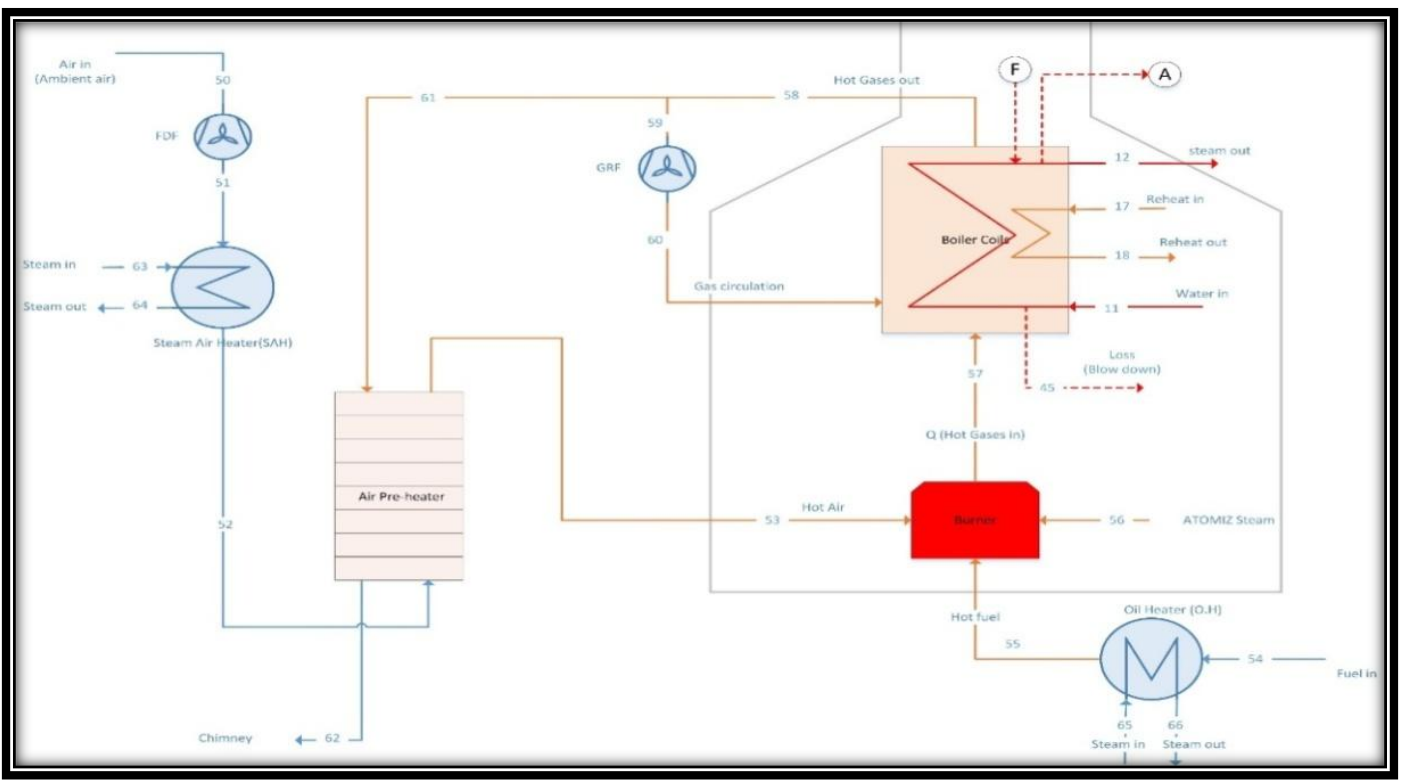

Fig2. Schematic diagram for the Boiler section of AL-Hartha station

\section{Theoretical AnAlysis}

A simplified program applicable to weigh up the cycle act of Al-Hartha power generation station is developed using the 1st and 2nd laws of thermodynamics. The mass, energy and exergy balance for each component as well as for the entire plant are introduced to study and to assess their performance. Consideration is taken here of the fact that this plant is designed to operate with specified power with limitations for some operating parameters. The cycle for this plant is laid out in Fig. (1) \& (2), labeled with numbers at different points.

\subsection{General Principles for the Analysis}

The general formulations of the mass, energy, entropy and exergy balances of the working fluid streams undergoing a steady state-steady flow processes through the plant components can be expressed by the following equations:

The mass rate balance equation is given by:

$\sum_{i} \dot{m}_{i}=\sum_{e} \dot{m}_{e}$

Where $\dot{m}$ is the mass flow rate. The subscripts $i$ and $e$ are denoted to the entrance and exit respectively. 
The Energy Balance Equation is given by:

$\sum \dot{Q}_{k}+\dot{m}_{i}\left(h_{i}+\frac{c_{i}^{2}}{2}+g Z_{i}\right)=\dot{m}_{e}\left(h_{e}+\frac{c_{e}^{2}}{2}+g Z_{e}\right)+\dot{W}$

Where:

$\sum \dot{Q}_{k}$ : is the net heat rate transfer through the process. The subscript $\mathrm{k}$ refers to the individual number of heat transfer locality

$h:$ is the enthalpy of the flowing stream, $c:$ is the flowing velocity, $g:$ is the gravitational acceleration, $Z$ : is the elevation of the flowing stream from a specified datum, $\dot{W}$ : is the net work rate transfer through the process.

The Exergy Balance Equation based on the second law of thermodynamic is given by:

$\sum\left(1-\frac{T_{o}}{T_{K}}\right) Q_{K}+\sum_{i} \dot{m}_{i} \psi_{i}=\dot{\Psi}_{W}+\sum_{e} \dot{m}_{e} \psi_{e}+I_{\text {dest }}$

Where:

$\sum\left(1-\frac{T_{o}}{T_{K}}\right) Q_{K}:$ is the net exergy rate due to heat flow, $T_{o}:$ is the reference environmental temperature, $T_{K}$ : is the stream temperature at position number $\mathrm{k}, \dot{\Psi}_{W}$ : is the exergy due to work transfer through the process, $\psi:$ is the exergy of the flowing stream, which is the sum of kinetic exergy , potential exergy, physical exergy, and chemical exergy, $\psi_{p h}$ is the physical exergy [6]:

$\psi_{p h}=\left[\left(h-h_{o}\right)-T_{o}\left(s-s_{o}\right)\right]$

Where:

$s:$ is the entropy of stream, $h_{o}, s_{O}$ : are the enthalpy and entropy of stream at reference environment conditions.

The chemical exergy is given by [7]:

$\left.\psi_{c h}=\left[\sum x_{i} \overline{e x}_{c h}^{i}+R T_{o} \sum x_{i} \ln x_{i}\right)\right] / M W_{\text {mix }}$

Where:

$x$ : is the kmole fraction of the gas component found in the gas mixture, $\overline{e x}_{c h}^{i}$ : is the chemical exergy of the individual gas component per kmole of component, $R$ : is the universal gas constant, 8.314 $\mathrm{kJ} / \mathrm{kmole} . \mathrm{K}, M W_{\text {mix }}$ : is the molecular weight of the gas mixture.

The Irreversibility rate which is also referred as the destroyed exergy is denoted by $I_{\text {dest }}$. This term can be calculated from eq. (3) or by applying the entropy generation principle given by [8]:

$I_{\text {dest }}=T_{o} \dot{S}_{g e n}$

Where:

$\dot{S}_{g e n}$ : is the entropy generation which can be calculated from the general entropy balance equation given by [9]:

$\dot{S}_{g e n}=\sum_{e} \dot{m}_{e} s_{e}-\sum_{i} \dot{m}_{i} s_{i}-\sum \frac{\dot{Q}_{K}}{T_{K}}$

\subsection{Thermodynamic Simulation of Al-Hartha Station Components}

Using the above general thermodynamic equations, the mathematical model for each component of Al-Hartha power station can be applied. The overall system performance is also can be evaluated under some operating conditions and assumptions. Each component is denoted with a numbers at the inlet and outlet, the properties of each point in the station is denoted at the same number shown in Fig. (1) and (2). The assumptions incorporated in the analysis for simplifying the problem are:

- Steady state operation for all components.

- All kinetic and potential terms are negligible. 
- Air is modeled as an ideal gas with variable properties and has a composition of $\mathrm{O}_{2}, \mathrm{~N}_{2}$ and $\mathrm{H}_{2} \mathrm{O}$

- Non isentropic operation is assumed for the fans, pumps and turbines.

- Produced gases from Combustion is modeled as an ideal gas mixture with variable properties [10].

- The gland steam extracted from the high pressure glands is only taking into account, while the gland steam extracted from the intermediate and low pressure turbine are neglected.

The overall energy efficiency for a device, system or station, can be expressed as:

$\eta_{\text {I.overall }}=\frac{\text { Net energy output }}{\text { Energy input }}$

Similarly, for the exergy efficiency for a device, system or station is calculated as follows:

$\eta_{\text {II.overall }}=\frac{\text { Net } \text { work outp ut }}{\text { Exergy input }}$

The thermal efficiency of the thermodynamic steam cycle $\left(\eta_{I . t h}\right)$ represents the ratio of the total net power generated from the steam cycle to the heat rate supplied at the boiler:

$\eta_{I . t h}=\frac{\text { Net power }}{\text { Energy rate input to the steam cycle }}=\frac{\dot{W}_{H P T}+\dot{W}_{I P T}+\dot{W}_{L P T}-\dot{W}_{C p}-\dot{W}_{B F P}-\dot{W}_{\text {boiler }}}{\left[\left(\dot{m}_{12}-m_{F}\right)\left(h_{12}-h_{11}\right)+m_{17}\left(h_{18}-h_{17}\right)+\right.}$

The exergy efficiency of the thermodynamic steam cycle $\left(\eta_{I I . t h}\right)$ represents the ratio of the total net power generated from the steam cycle to the exergy supplied at the boiler:

$\eta_{I I . t h}=\frac{\text { Net power }}{\text { Exergy input to the steam cycle }}=\frac{\frac{\dot{W}_{H P T}+\dot{W}_{I P T}+\dot{W}_{L P T}-\dot{W}_{C p}-\dot{W}_{B F P}-\dot{W}_{\text {boiler }}}{\left[\left(\dot{m}_{12}-m_{F}\right)\left(\psi_{12}-\psi_{11}\right)+\dot{m}_{17}\left(\psi_{18}-\psi_{17}\right)+\right.}}{\left.m_{45}\left(\psi_{45}-\psi_{11}\right)+m_{A}\left(\psi_{A}-\psi_{11}\right)+m_{F}\left(\psi_{F}-\psi_{11}\right)\right]}$

The overall boiler energy and exergy efficiency is calculated by the following equation:

$$
\begin{aligned}
& \eta_{I . b o i l e r}=\frac{\text { energy of produced steam }}{\text { energy input by fuel }}=\frac{\begin{array}{c}
{\left[\left(\dot{m}_{12}-\dot{m}_{F}\right)\left(h_{12}-h_{11}\right)+\dot{m}_{17}\left(h_{18}-h_{17}\right)+\right.} \\
\left.\dot{m}_{45}\left(h_{45}-h_{11}\right)+m_{A}\left(h_{A}-h_{11}\right)+m_{F}\left(h_{F}-h_{11}\right)\right]
\end{array}}{\dot{m}_{f} * L H V} \\
& \eta_{\text {overall .boiler }}=\frac{\text { exergy of produced steam }}{\text { exergy input by fuel }}=\frac{\left.\dot{m}_{45}\left(\dot{m}_{12}-\dot{m}_{F}\right)\left(\psi_{12}-\psi_{11}\right)+\dot{m}_{17}\left(\psi_{18}-\psi_{17}\right)+m_{A}\left(\psi_{A}-\psi_{11}\right)+m_{F}\left(\psi_{F}-\psi_{11}\right)\right]}{m_{f} * H H V}
\end{aligned}
$$

The energy and exergy efficiencies for the power station can be written as:

$$
\begin{aligned}
& \eta_{I . p l a n t}=\frac{\dot{W}_{H P T}+\dot{W}_{I P T}+\dot{W}_{L P T}-\dot{W}_{C p}-\dot{W}_{B F P}-\dot{W}_{\text {boiler }}}{m_{f} * L H V} \\
& \eta_{I I . p l a n t}=\frac{\dot{W}_{H P T}+\dot{W}_{I P T}+\dot{W}_{L P T}-\dot{W}_{C p}-\dot{W}_{B F P}-\dot{W}_{\text {boiler }}}{\dot{m}_{f} * H H V} \\
& \dot{W}_{\text {boiler }}=\left(\dot{W}_{G R F}\right)_{\text {elc }} * \eta_{\text {elc.GRF }} * \eta_{\text {mec } h . G R F}+\left(\dot{W}_{F D F}\right)_{\text {elc }} * \eta_{\text {elc. FDF }} * \eta_{\text {mec } h . F D F}
\end{aligned}
$$

\section{RESULTS AND DisCUSSION}

The results that will be reviewed in this section are for the first unit of AL-Hartha station. All mathematical equations were established for the processes through the station are modeled using EESsoftware. The original design data values of the executing company for AL-Hartha steam power station are obtained from the operational manuals and maintenance reports. The related daily operating data is obtained from the daily follow-up the recordings operation log sheets along fully one year of 2016. The reference environment properties are defined as the ambient conditions at the station location. The results deals with the actual performance of the station using the actual daily registered operating data to identify its current efficiency and to indicate the percentage of participation of the station components in the energy/exergy lost or destroyed. Prior to all of the above mentioned contents of this chapter and for the purpose of proving the validity and accurate runs of the simulated program, the simulated results are compared with the design data of AL-Hartha power station and with the similar results that obtained by other researcher. 


\subsection{Mathematical Model Verification}

Initially, the actual operating data for AL-Hartha power station are used to calculate the generated power using the present model. The calculated daily average power values along one month (July) are shown in Fig.(3) together with the practical registered values for the same period. The extent of convergence between these results with a percentage is of a maximum deviation of (1.8\%). Next, the practical data of coal-based Indian thermal power station of $210 \mathrm{MW}$ under operation at different loads is adopted in the current mathematical model for calculation the thermal and exergitic efficiency. The results are shown in Fig.(4) together with that obtained by S. Sengupta et al [3]. This figure shows the similarity extent between the obtained results with a greatest error of $1.6 \%$.

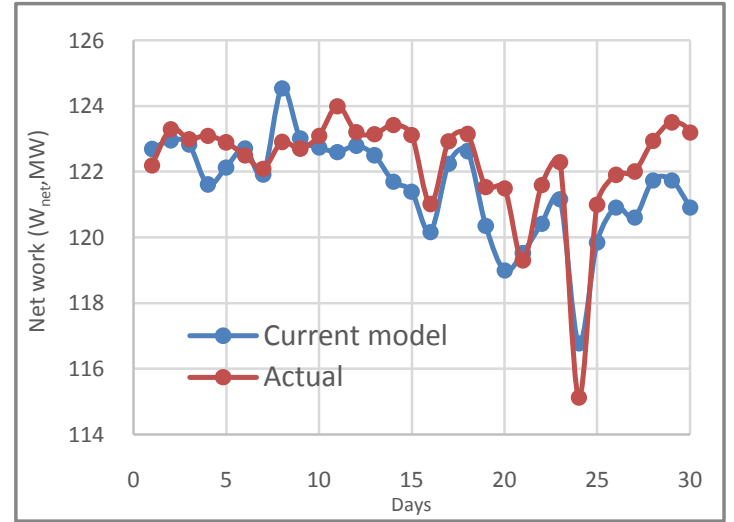

Fig3. The extent of compatibility between the results of the current model with the practical results during the month of July 2016

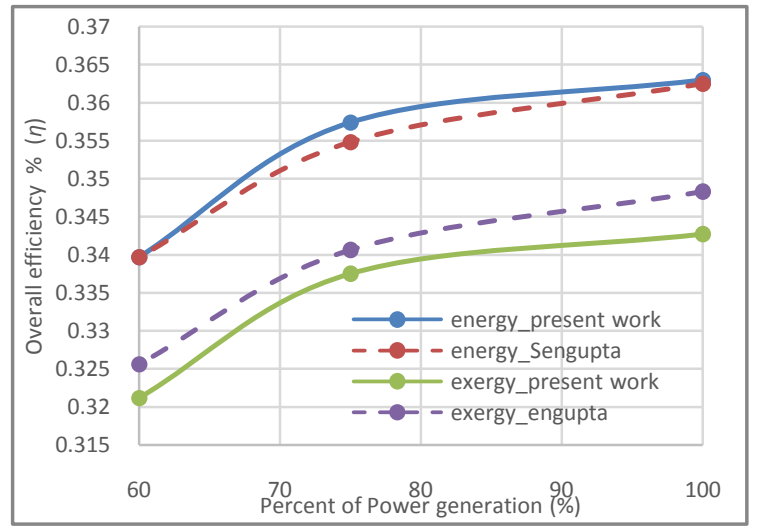

Fig4. comparison of the results of the present thermodynamic model against the result of Sengupta [3]

\subsection{Results of Thermodynamic Analysis of AL-Hartha power Station}

Based on the actual operational data of the station, the performance results will be demonstrated and discussed.

\subsubsection{General Results and Observations}

From the observation and follow-up of the daily work of Hartha station for a full year of 2016, the first power generation unit involved in this study produces about 118 to $126 \mathrm{MW}$ actual power. Although the aim of the station is to get the highest capacity that can continuously produced, There is a fluctuation in the power production. It depends on the fluctuation in the variables of daily operating factors and the possibility of malfunction in some of the station machinery, which necessitates direct intervention by the station workers to prevent the occurrence of serious failures due to pressure fatigue or high temperature stresses. Some of these factors are the ambient temperature, the temperature and level of the river water which is used as the condenser cooling media and others. The ambient temperature difference between night and day is about $20^{\circ} \mathrm{c}$ in the summer and about $10^{\circ} \mathrm{c}$ in winter. The ambient temperature difference between summer and winter is more than $25^{\circ} \mathrm{c}$. The change in river water temperature is more than 20 degrees between winter and summer. When the faults are serious and uncontrolled, the station management may issues orders for a general shut down of the station until the fault is cleared which may need several days.

\subsection{Discussion the Results of the Actual Thermal Performance of AL-Hartha power Station}

The resulting power, thermal efficiency and the amount of heat lost to the external environment are the most important factors for thermally evaluating the station based on the first law of thermodynamics. Figure (5) shows the daily produced power for three different days: 21 July, 21 May and 21 January, while Figure (6) shows the alteration of the average power generation through months along one year. Apart from the impact of environmental factors, it is noted in Figure (6) that the resulting power has experienced a decline in value during the months of December and October compared to the hotter months that preceded it. At that period, there were sudden and serious failures 
in the fifth and sixth feed water heaters, which forced the workers in the station to separate these exchangers from the working cycle and then shut-down the station for several days. Separating two feed water heaters in turn led to a decrease in the mean temperature of water supplied to the boiler and so in the generated power despite the continued decrease in the condensation pressure at that time.

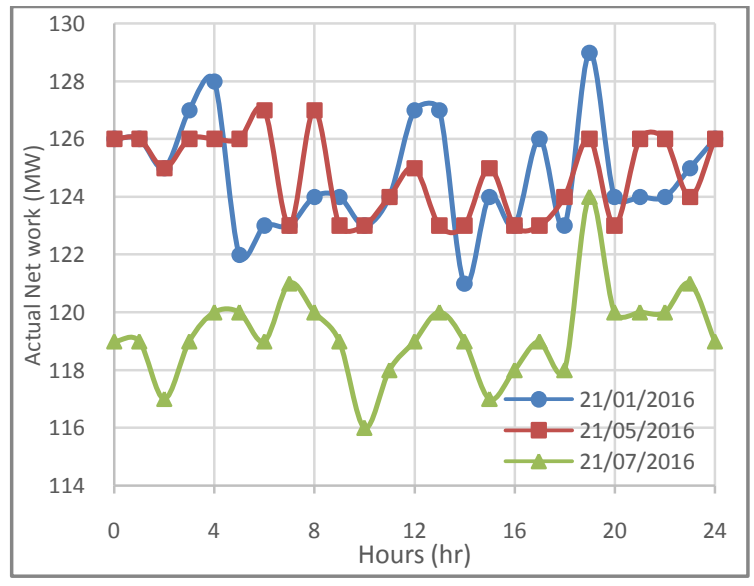

Fig5. variation of net work with the daily hours

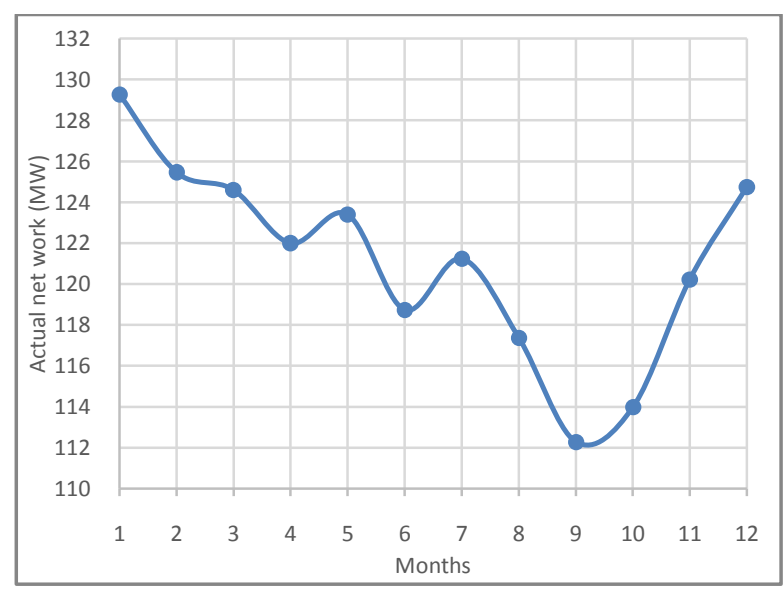

Fig6. variation of actual mean generated power through months along one year

It is known that the reduction of vacuum due to increasing of the condenser cooling water temperature as in summer leads to reduce the generated power. Figure (7) shows the mean condenser pressure changes in months along one year, there is a significant increase in the pressure in July than in the other months due to the change in the state of condenser cooling water of Shut-alarab river. Figure (8) shows the thermal efficiency fluctuation of the power cycle for the months of the year 2016. This shows that the thermal efficiency does not exceed $0.373 \%$ in its best condition and decreases in the hot months to $0.345 \%$, with an annual rate of $0.357 \%$.

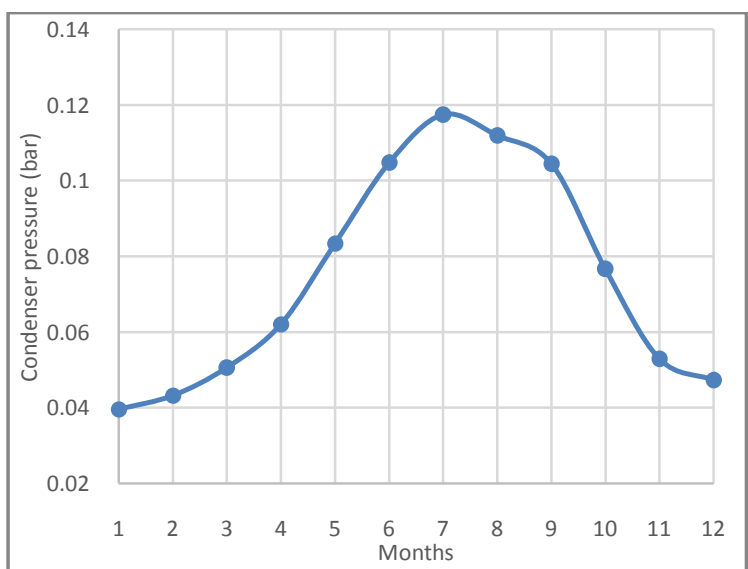

Fig7. shows the mean Condenser pressure of months during the year 2016

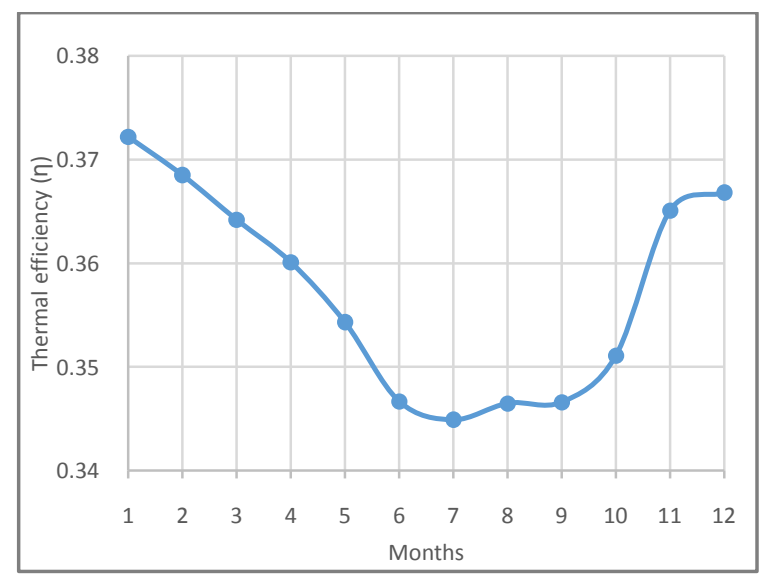

Fig8. Variation of the cycle actual thermal efficiency through months of year 2016

Figure (9) shows the lost thermal energy percentages in the condenser, blow down water at the boiler, with the flue gases and other thermal losses through boiler walls, heat exchangers and due to mechanical losses. It can be noted that about $51 \%$ of total energy input to the station is lost in the condenser, $7 \%$ at the exhaust gases. $0.88 \%$ in the blow down, and an infinitesimal of losses energy occurred in the fuel preheater and steam air preheater. In a more comprehensive look at the station performance evaluation, the overall efficiency can be reviewed as it represented in Figure (10). The overall efficiency during the months of the year dose not exceed $0.342 \%$ at their best with an annual overall efficiency rate of $0.33 \%$. By comparing the actual performance of the station, the actual cycle thermal efficiency of the station appears to be below the design condition which was of $43 \%$. Also, the actual overall thermal efficiency (33\%) is less than the design value which was of about $39 \%$. 


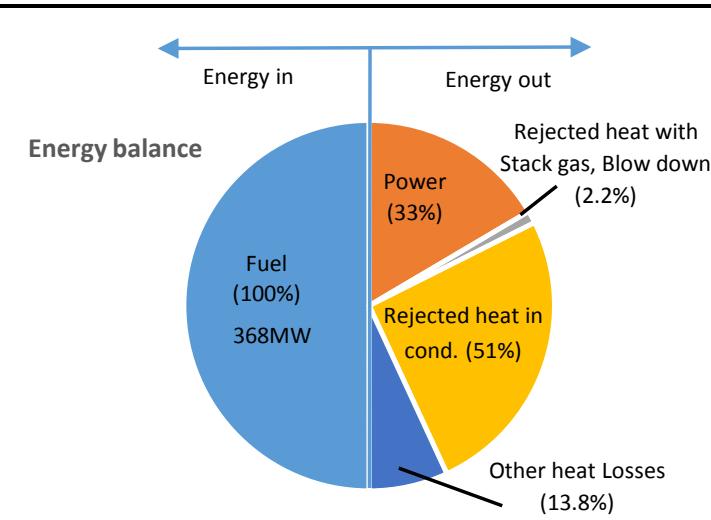

Fig9. The percent of actual energy balance in the main sections of the station

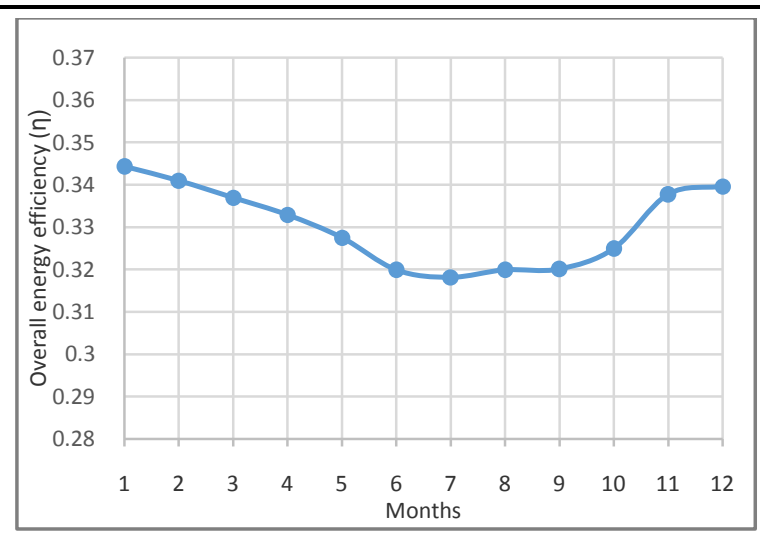

Fig10. the actual overall energy efficiency of the station during the months of the year 2016

\subsection{Discussion the results of the actual exergitic performance of Al-Hartha station}

Whatever the amount of thermal energy lost with the condenser cooling water or at any other component, this energy cannot be fully used or regenerated for other uses if its quality is low. It is better to look for the possibility of taking advantage of the high-quality thermal energy (exergy), so it is needed to identify its location among the station components. The total calculated value of the destroyed exergy in the main components of the station is $253.6286 \mathrm{MW}$. Figure (11) shows that the average destroyed exergy at the condenser is $6.465 \mathrm{MW}(2.549 \%$ of the total destroyed exergy in the station). This is too small relative to the large amount of low grade heat energy lost at the condenser $(51 \%)$.

Figure (12) shows that the values of the destroyed exergy in the boiler sector are ranging from 216 to $245 \mathrm{MW}$ for different months during the year, with an average value of $229 \mathrm{MW}$ which represent $90.29 \%$ of the total destroyed exergy in the station with an exergitic efficiency of $75.5 \%$. The larger amount of this destructed exergy in the boiler sector is due to irreversibility in the boiler coils which causes an average destroyed exergy of $125.3 \mathrm{MW}$ that represent $49.4 \%$ of the total exergy destroyed in the station. The fuel burning process in the burner causes an exergy destruction of about $97 \mathrm{MW}$ or $38.2 \%$ of the total destroyed exergy in the station. The remaining quantities are destroyed in the other components of the boiler section such as the rotary air preheater, fuel preheater, FDF and GRF. The mean exergitic efficiencies of the boiler sector are $50.2 \%$ at the boiler heating coils, and $69.1 \%$ at the the Burner. The significant exergy destruction in the boiler section can be attributed to the inefficient combustion processes, heat transfer through finite temperature difference within the boiler coils and walls and due to fouling and soot deposits on the surfaces.

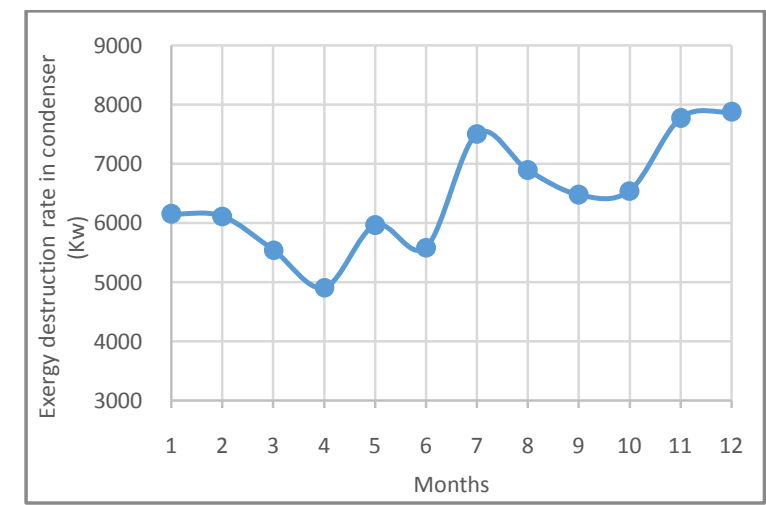

Fig11. shows the exergy destruction in the condenser

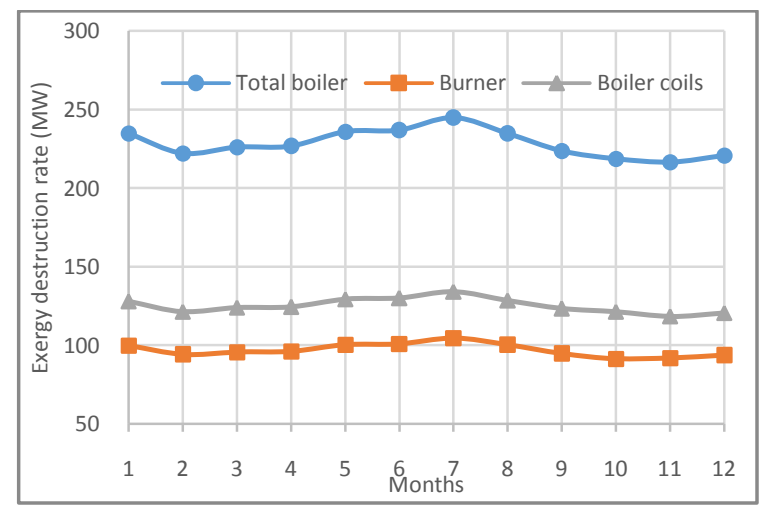

Fig12. shows the exergy destruction rate at the boiler sector, boiler coils, and Burner of AL-Hartha power Station during the year 2016

It is noted in Figure (13) that the destroyed exergy at the low pressure turbine is more than that at the other, followed by the high pressure turbine. The average destructed exergy of all these turbines is with an average value of $13.88 \mathrm{M}$ which represent $5.474 \%$ of the total destroyed exergy in the station. The average exergitc efficiencies are $(80.6 \% \%)$ for HPT and $(83.89 \%)$ for IPT and $(81.42 \%)$ for 
LPT. The average exegitic efficiency of the turbines sector is (81.8\%). Figure (14) demonstrates the destructed exergy in the feed water heaters. Note that there are clear disparities in the performance of each FWH during the year, which indicates that they are experienced a frequent failures and that the repairs are not radical. However, the destroyed exergy by all these exchangers does not exceed $(1.58 \%)$ of the total destroyed in the station with an average value of $4.01 \mathrm{MW}$. The highest mean destroyed quantity is in the fourth FWH, followed by the sixth, first, second, fifth and third.

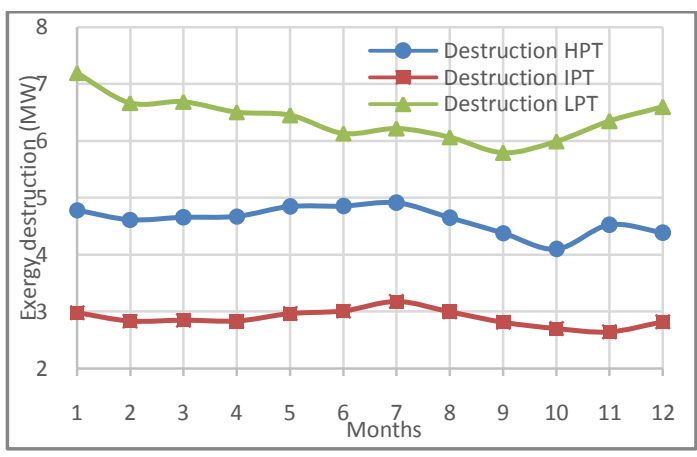

Fig13. shows the exergy destruction rate in the HPT, $I P T$, and LPT in the AL-Hartha power Station during year 2016

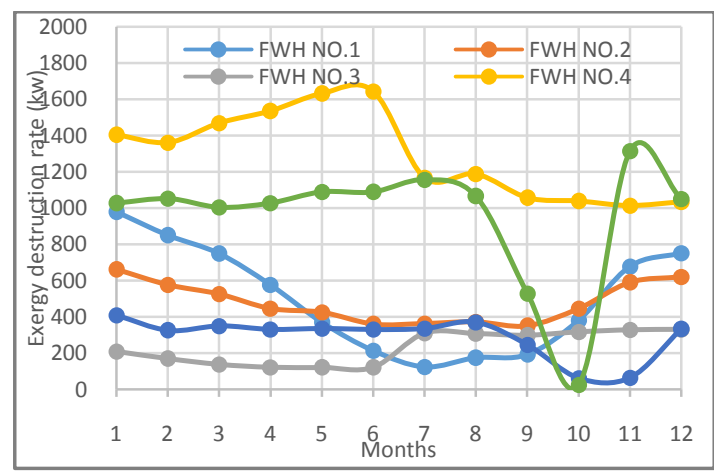

Fig14. shows the exergy destruction rate in the FWHs in the AL-Hartha power Station during year 2016

Figure (15) demonstrates the destructed exergy in the condensate pump and feed water pump. The destroyed exergy by these two pumps does not exceed $229 \mathrm{KW}$ or $9 \%$ of the total destroyed in the station. The feed water pump occupies the bulk of this quantity $(201 \mathrm{~K})$ with exergitic efficiency of $881.35 \%$ for the condensate pump and $83.59 \%$ for the feed water pump. The destroyed exergy in the Expansion valves is due to irreversibility of expansion process and found too small with about $1.11 \%$ of the total destroyed in the station. Figure (16) summarizes the values of participation of each component by destroying the exergy. Of all the components of the station, the boiler sector occupies the first place, although its thermal efficiency has exceeded 50\%. The boiler sector is the most exergy destructive component by $90.3 \%$, and is followed by the group of turbines by $5.47 \%$ and the condenser by $2.55 \%$ and then the group of feed water heaters by $1.58 \%$, while the rest of the components, such as water pumps and expansion valves, share too little to have significant effect.

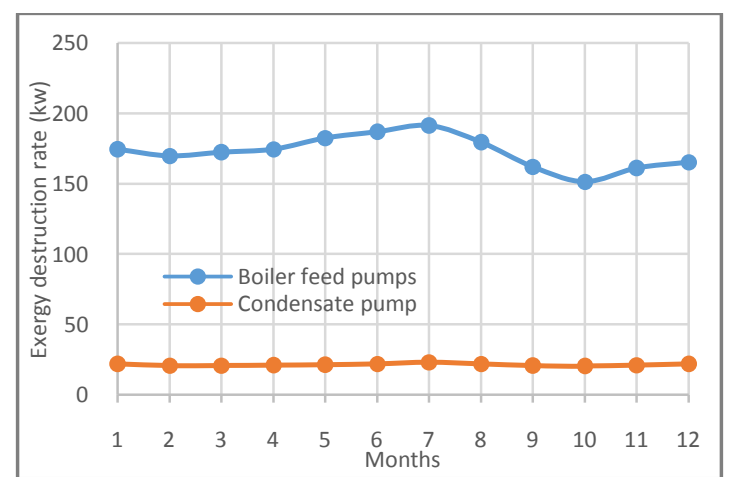

Fig15. shows the exergy destruction rate in the Pumps (BFP, CP) in the AL-Hartha power Station during year 2016

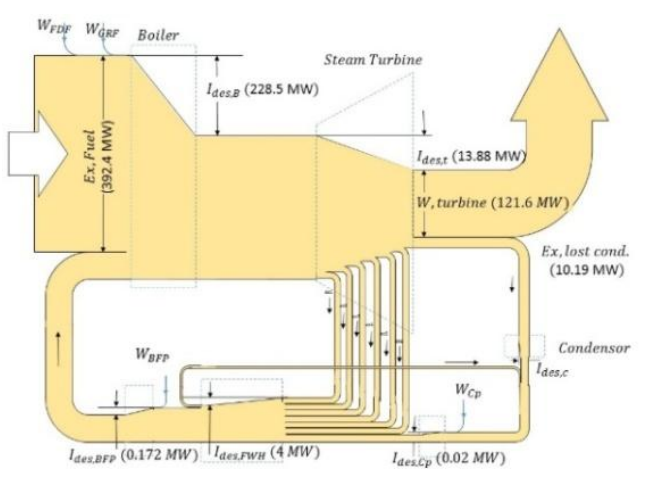

Fig16. The Grassman diagram (exergy flow diagram) for Actual analysis of AL-Hartha power station

Of the total amount of destructed exergy throughout the station as whole, it is possible to give a comprehensive view of the station's exegetic efficiency as shown in Figure (17), where the value is reduced in the hot months of the year. The average exegetic efficiency is $30.6 \%$. This value is close to the thermal efficiency of the station ( $33 \%$ ).

Spaced out from the destroyed fractions of exergy, there are quantities of lost exergy through the components of the station as summarized in table (1). These available energy (18.712 MW) which represents the available energy that has not been utilized to do work. It may can be recovered based on how well the station component are perform. It represent a significant opportunity to invest in improving the station's performance. 
It is possible to follow up the characteristics of some parts of the station that were not mentioned in the course of the discussion, by reviewing table(2), which includes the results of the analysis of the all components that handled by the mathematical model of this study. The destroyed exergy cannot be totally avoided because it is due to the irreversibility, it requires radical modifications in the designs based on the diagnosis of damage caused to some parts due to the aging and accidents that hit the station during the previous periods.

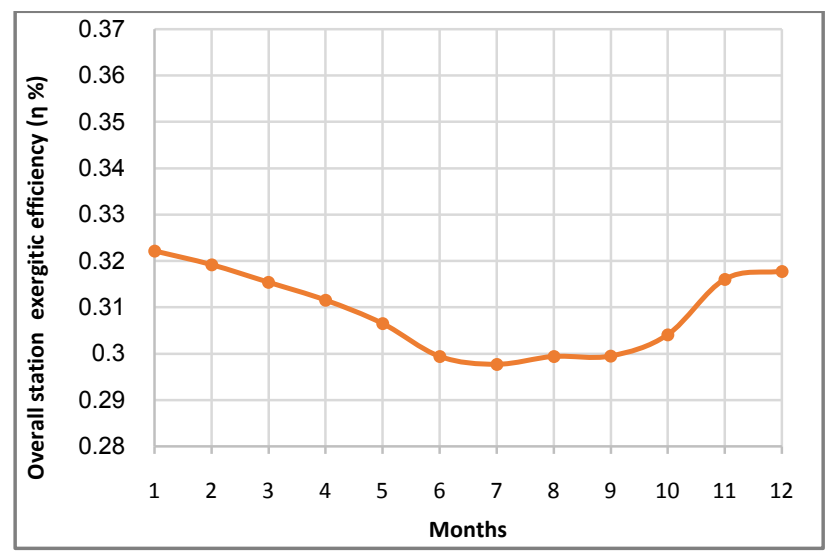

Fig17. Shows the overall station exergitic efficiency with months during a year 2016

Table1. Exergy losses distribution through Al-Hartha power station components

\begin{tabular}{|c|c|c|}
\hline \multicolumn{3}{|c|}{ Exergy losses in AL-Hartha power station at 2016 } \\
\hline Location & Exergy losses rate $(\mathbf{k W})$ & Percentage \% \\
\hline Condenser & 7402.4 & 39.56 \\
\hline Exhaust gases & 3939.17 & 21.05 \\
\hline Blow down & 1192.3 & 6.37 \\
\hline Boiler walls & 6178.3 & 33.02 \\
\hline Total & 18712.17 & 100.00 \\
\hline
\end{tabular}

\begin{tabular}{|c|c|c|c|c|}
\hline \multicolumn{5}{|c|}{ Exergy sheet for AL-Hartha Power station at 2016} \\
\hline \multirow[t]{2}{*}{ Station component } & \multirow[t]{2}{*}{ Work $(k \mathbf{W})$} & \multicolumn{2}{|c|}{ Exergy destruction } & \multirow[t]{2}{*}{ Exergy Efficiency } \\
\hline & & $\mathbf{k W}$ & (\%of total) & \\
\hline \multicolumn{5}{|c|}{ Power Production Device } \\
\hline HPT & 35747.7 & 4613.83 & 1.8191 & 0.8061 \\
\hline IPT & 35639.3 & 2882.67 & 1.1366 & 0.8389 \\
\hline LPT & 54954.73 & 6388.00 & 2.5186 & 0.8142 \\
\hline Turbine Total & 126341.73 & 13884.5 & 5.4743 & - \\
\hline \multicolumn{5}{|c|}{ Feed Water Heater } \\
\hline FWH NO.1 & - & 503.08 & 0.1984 & 0.7658 \\
\hline FWH NO.2 & - & 478.23 & 0.1886 & 0.8018 \\
\hline FWH NO.3 & - & 231.16 & 0.0911 & 0.8358 \\
\hline FWH NO.4 & - & 1295.00 & 0.5106 & 0.8753 \\
\hline FWH NO.5 & - & 290.94 & 0.1147 & 0.7946 \\
\hline FWH NO.6 & - & 952.35 & 0.3755 & 0.8559 \\
\hline GSC & - & 143.29 & 0.0565 & 0.112 \\
\hline SJAE & - & 118.13 & 0.0466 & 0.02421 \\
\hline FWH Total & - & 4012.18 & 1.5819 & - \\
\hline \multicolumn{5}{|c|}{ Condenser } \\
\hline Cond & - & 6446.3 & 2.5416 & 0.267 \\
\hline HW & - & 18.20 & 0.0072 & 0.794 \\
\hline Total & - & 6464.5 & 2.5488 & - \\
\hline \multicolumn{5}{|c|}{ Pumps } \\
\hline $\mathrm{CP}$ & 223.2 & 27.71 & 0.0109 & 0.8135 \\
\hline BFP & 2424.5 & 201.2 & 0.0793 & 0.8359 \\
\hline Total & 2647.7 & 228.91 & 0.0903 & - \\
\hline
\end{tabular}


Abdullah N. Fadhil et al.

\begin{tabular}{|c|c|c|c|c|}
\hline \multicolumn{3}{|c|}{ Expansion Valves } \\
\hline EV.NO.1 & - & 2.710 & 0.0011 & 0.330 \\
\hline EV.NO.2 & - & 6.032 & 0.0024 & 0.333 \\
\hline EV.NO.3 & - & 5.547 & 0.0022 & 0.806 \\
\hline EV.NO.4 & - & 0.528 & 0.0002 & 0.935 \\
\hline EV.NO.5 & - & 0.230 & 0.0001 & 0.957 \\
\hline EV.NO.6 & - & 5.619 & 0.0022 & 0.963 \\
\hline EV.NO.7 & - & 7.503 & 0.0030 & 0.970 \\
\hline Total & - & 28.169 & 0.0111 & - \\
\hline BC & - & Boiler & & 0.5021 \\
\hline BU & - & 125296.75 & 49.4017 & 0.6911 \\
\hline APH & - & 96998.00 & 38.2441 & 0.589 \\
\hline SAH & - & 4482.08 & 1.7672 & 0.158 \\
\hline FH & - & 1569.98 & 0.6190 & 0.238 \\
\hline FDF & 540.5 & 267.52 & 0.1055 & 0.793 \\
\hline GRF & 1543.2 & 129 & 0.0509 & 0.771 \\
\hline Total & 2083.7 & 229010.33 & 90.2936 & - \\
\hline
\end{tabular}

\subsection{Discussion the Results of the Actual Exergitic Performance of AL-Hartha Station}

Spaced out from the destroyed fractions of exergy, there are quantities of lost exergy through the components of the station. These available energy (18.712 MW), may can be recovered based on how well the station components are performed, and it represent a significant opportunity to invest in improving the station's performance.

The lost amount of exergy, which represents the available energy that has not been utilized to do work is about $18.712 \mathrm{MW}$ or more by some of the losses that were not considered in this study at the components that are considered as adiabatic or are completely isolated. These losses are distributed on the main components that cause it as summarized in table (1).

The exergy losses at the exhaust gasses also significant but can't be totally recovered in order to maintain the exhaust gasses at a temperature above $120^{\circ} \mathrm{C}$ to prevent acid rain. This is also the case with the amount of the exergy lost at the condenser as water is present at a low temperature level. At the same time, the chance to benefit from the exergy lost due to thermal radiation from the boiler chamber walls (33\% of the lost exergy), can be achieved by enhancing thermal insulation with improving the heat transfer through the pipes of boiler coils that suffer from insulating accumulations. The exergy lost in the blow down is at high quality energy and represent more than $6 \%$ of the lost exergy.

\section{Conclusions}

1. The simulation model for AL-Hartha power station with the overall thermodynamic analysis based on the first and second laws of thermodynamics is successfully developed, simulated and applied to study the actual performance of the station under operation.

2. AL-Hartha Station with four production units currently operating with one unit only. This unit produces a total power of about $120 \mathrm{MW}$, which means that this unit operates at $60 \%$ of its design capacity. The actual overall thermal efficiency of this unit is $33 \%$ with an exergitic efficiency of $30.6 \%$, while the deign overall thermal efficiency is $39 \%$.

3. Based on $1^{\text {st }}$ law analysis, the actual thermal energy lost from the station at the condenser alone is estimated at $51 \%$ of the fuel energy. This amount of lost energy is considered to be of low grade energy because it is rejected at a temperature of $23{ }^{\circ} \mathrm{C}$ to $41^{\circ} \mathrm{C}$. The lost thermal energy in other components are $0.88 \%$ in the blow down, $7 \%$ at the exhaust gases, which is small but is of high grade energy $\left(151^{\circ} \mathrm{C}\right)$, and thus can be used heavily to pre-heat the air before combustion by integrating the heat recovery system into the station. An infinitesimal losses of thermal energy occurred in the fuel preheater and steam air preheater.

4. The alteration in the power production during the hours of the day and during the months and seasons, depends on the variation of climatic and environment conditions in addition to the actions taken by the employers at the station to avoid high pressure and the degree of superheat to prevent the occurrence of the thermal and mechanical stresses in the boiler. 
5. Performance analysis based on the $2^{\text {nd }}$ law of thermodynamics helped to determine which sites within the station are the most important cause of the impact of the available energy losses and has most influential impact on performance.

6. The average exegetic efficiency of the station is $30.6 \%$. The most important sites affecting the exergitic performance of the station is the boiler sector, which resulted in losses of available energy equivalent to $90.3 \%$ of the total exergy losses in the station, distributed by $49.4 \%$ at the boiler coils and by $38.24 \%$ at the fuel burner, the remaining are distributed at the other parts of the boiler section. This indicates that a feasible opportunities are available for improvement by a suitable modification to reduce the destructed exergy. However, part of this irreversibility cannot be avoided due to physical, technological, and economic constraints.

7. The second component in the order that has most influential effect on the station performance is the turbine section, which resulted in losses of an available energy equivalent to about $5.475 \%$ of the total exergy losses in the station, distributed by $2.519 \%$ at the LPT, $1.137 \%$ at the IPT and by $1.819 \%$ at the HPT.

8. Except for the destroyed exergy, there are quantities of exergy lost to surrounding. This amount is estimated at $18.712 \mathrm{MW}$. This amount of available energy represents a good opportunity to take advantage of it to improve the station's performance.

9. The water temperature of the Shat al-Arab river is considered to be a major factor influencing the capacity and efficiency of the station as it is has a direct influence on the condensation pressure. So it is advisable to recommend the use of cooling tower to maintain low cooling water temperature.

10. The reference atmospheric temperature forms an indirect factor affecting the performance, where the station performance improves in the cold times and become less in hot times both on a day-toyear basis

\section{ACKNOWLEDGEMENT}

The authors are grateful to the staff and management of AL Hartha Steam Power Station for their cooperation, support and helpful with providing the information and daily actual operation data used in the present study.

\section{LIST OF SYMBOLS}

\begin{tabular}{|c|l|c|l|}
\hline English symbols: & & gen & Generation \\
\hline$c$ & Velocity $(\mathrm{m} / \mathrm{s})$ & $i, e$ & Inlet and exit \\
\hline$g$ & Gravitational acceleration $\left(\mathrm{m} / \mathrm{s}^{2}\right)$ & $m e c h$ & Mechanical \\
\hline$h$ & Enthalpy $(\mathrm{kJ} / \mathrm{kg})$ & $m i x$ & Mixture \\
\hline$I$ & Irreversibility $(\mathrm{kW})$ & o & Environment state \\
\hline$\dot{m}$ & Mass Flowrate $(\mathrm{kg} / \mathrm{sec}$ & Abbreviations: & \\
\hline$Q$ & Heat $(\mathrm{kW})$ & $H P T$ & High pressure turbine \\
\hline$s$ & Entropy $(\mathrm{kJ} / \mathrm{kg})$ & $I P T$ & Intermediate pressure turbine \\
\hline $\mathrm{T}$ & Temperature $\left({ }^{\circ} \mathrm{C}\right)$ & $L P T$ & Low pressure turbine \\
\hline$W$ & Work $(\mathrm{kw})$ & $B F P$ & Boiler feed pump \\
\hline $\mathrm{X}$ & Mole fraction & $C P$ & Condensate pump \\
\hline$Z$ & Elevation $(\mathrm{m})$ & $G R F$ & Gas recirculation turbine \\
\hline Greek symbols: & & $F D F$ & Forced draft fan \\
\hline$\psi$ & Flow exergy $(\mathrm{kJ} / \mathrm{kg})$ & $F L T$ & First low of thermodynamic \\
\hline$\dot{\Psi}$ & Exergy due to work $(\mathrm{kW})$ & $S L T$ & Second low of thermodynamic \\
\hline $\mathrm{I}$ & First law & $F W H$ & Feed water heater \\
\hline $\mathrm{II}$ & Second law & $E E S$ & Engineering equation solver \\
\hline$\eta$ & Efficiency & $S A H$ & Steam air heater \\
\hline Subscripts: & & $A P H$ & Air pre heater \\
\hline$c v$ & Control volume & $O H$ & Oil heater \\
\hline$C h$ & Chemical & $H H V$ & Higher heating value \\
\hline dest & Destruction & $L H V$ & Lower heating value \\
\hline$e l c$ & Electrical & MW & Molecular weight \\
\hline ex & exergy & & \\
\hline$f$ & Fuel & & \\
\hline
\end{tabular}




\section{REFERENCES}

[1] U. EIA, "International energy statistics," US Energy and Information Administration, Washington, DC [available at http://www. eia. gov/countries/data. cfm], 2011.

[2] M. A. Rosen, "Energy-and exergy-based comparison of coal-fired and nuclear steam power plants," Exergy, An International Journal, vol. 1, pp. 180-192, 2001.

[3] S. Sengupta, A. Datta, and S. Duttagupta, "Exergy analysis of a coal-based $210 \mathrm{MW}$ thermal power plant," International Journal of Energy Research, vol. 31, pp. 14-28, 2007.

[4] I. H. Aljundi, "Energy and exergy analysis of a steam power plant in Jordan," Applied Thermal Engineering, vol. 29, pp. 324-328, 2009.

[5] G. R. Ahmadi and D. Toghraie, "Energy and exergy analysis of Montazeri steam power plant in Iran," Renewable and Sustainable Energy Reviews, vol. 56, pp. 454-463, 2016.

[6] J. M. Michael and N. S. Howard, "Fundamentals of engineering thermodynamics," Fundamentals of Engineering Thermodynamics, 2011.

[7] I. Dincer and M. A. Rosen, Exergy: energy, environment and sustainable development: Newnes, 2012.

[8] A. C. Yunus and A. B. Michael, "Thermodynamics: An engineering approach," McGraw-Hill, New York, 2006.

[9] Y. Cengel and M. Boles, Loose leaf for thermodynamics: An engineering approach: McGrawHill Education, 2014.

[10] F. A. Boyaghchi and H. Molaie, "Sensitivity analysis of exergy destruction in a real combined cycle power plant based on advanced exergy method," Energy Conversion and Management, vol. 99, pp. 374-386, 2015.

\section{AUTHORS' BIOGRAPHY}

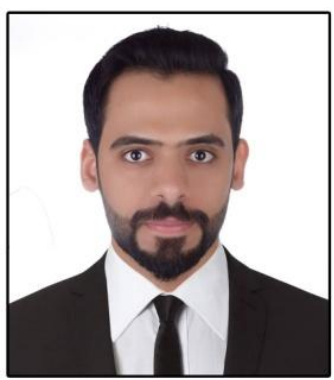

Abdullah Nasrallah Fadhil, is a Master of Thermal Engineering in Thermal Mechanical Engineering Department, Southern Technical University, Technical Engineering College of Basra, Iraq. He is having 3 years working experience as QA/QC Engineer in Oil and Gas Companies.

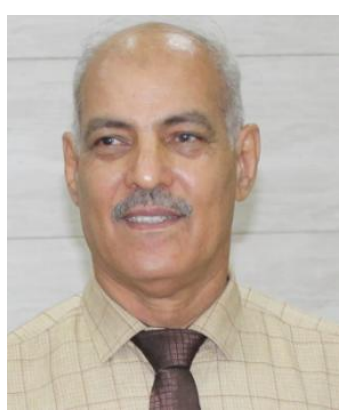

Dr. Abdulwadud Salman Shehab, is Assistant Professor holds his $\mathrm{PhD}$ from the SSSR in 1992. Prior to that, he received a master's degree from the University of Basrah in 1984 in Mechanical Engineering - Refractories. He has been teaching in his field for more than 30 years. Supervised a number of graduate students to obtain a doctorate and master's degree and has a number of research published in the national and internatioan journals. He was appointed to retire at his will in 2015 . His research interests in the field of refractories, refrigeration and air conditioning.

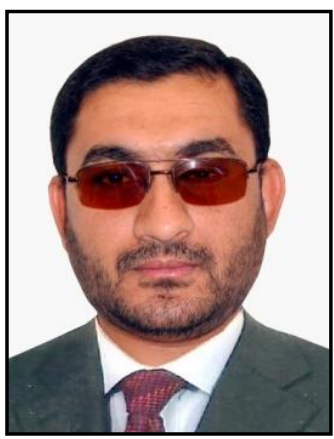

Dr. Safaa Hameed Faisal is presently working as instructor and dean assistant for student's affairs of Basra Engineering Technical College, Southern Technical University, Iraq. $\mathrm{He}$ is having 13 years teaching experience and presently four research students are doing their M.Sc research work under his cooperative supervision. His field of interest is heat transfer, energy, and exergy simulation of thermal systems. 